\section{Europe drafts a convention}

Europe has taken an important step towards making bioethics a legitimate topic of political debate, as well as a universal right that governments must respect.

Meeting last week in Madrid, the chairmen of the ethics committees from the 26 countries that make up the Council of Europe adopted a draft of a European Convention on Bioethics. Participants also agreed to become members of a standing conference that would promote discussion and raise awareness of their work.

The convention - due to be ready by the end of 1993 - will consist of a framework of fundamental principles, based loosely on the European Convention on Human Rights. It will incorporate respect for human dignity, protection of individual integrity and the prohibition of all commercial agreements concerning the human body and its organs. Subsequent protocols will contain the rules for specific fields of bioethics, the first two of which will cover organ transplantation and biomedical experiments on humans.

The terms of both the convention and the protocols are expected to be quite general. While such broad wording will not be very useful as a guide to decisions on specific cases, observers believe that the documents will serve to promote the discussion of bioethical issues across Europe. In addition, the convention is unlikely to eclipse national legislation in deciding what researchers are permitted to do.

The Standing Conference of National Ethics Committees will provide muchneeded channels of communication and allow bioethical issues to be debated on a pan-European scale. Catherine Lalumiere, secretary general of the Council of Europe and proposer of the conference, says that, in particular, bioethics must be discussed in the context of economic as well as scientific and legal issues.

Meanwhile, in Paris last week, three draft bioethics bills were presented to the French Council of Ministers for their consideration before being passed on to the spring session of Parliament. Few changes are expected to be made to the bills, which are couched in terms similar to the draft European convention. The French government hopes that this body of legislation, once passed, will become a reference point as its European neighbours and the United Nations discuss medical and genetic human rights. In 1983, France was the first country in Europe to set up a national ethics committee.

The three bills are sponsored by three different parts of the French government. The first bill, from Minister of Justice
Michel Sapin, concerns the law on genetic identity. It states that a person's genetic make-up should be modified only for therapeutic reasons. Genetic tests will be permitted only in scientific research, medical therapy, and judicial proceedings.

The second bill, from Health Minister Jean-Louis Bianco, concerns the use of human organs and products for therapeutic purposes. It calls for the donor to remain anonymous, and states that no financial remuneration should be made for any part of the human body. It also covers the donation of organs and tissue and medically assisted procreation, which includes anything from the use of fertility drugs to in vitro fertilisation. But it is silent on any diagnoses conducted before the egg is implanted in the womb. Such procedures have been prohibited in France since 1986.

The third bill is from Hubert Curien, minister of research and technology. It deals with the computerization and management of health and genetic data.

Also last week, in London, the Nuffield Council on Bioethics announced that a panel has been formed to examine genetic screening. The group will look at the techniques involved, their benefits and difficulties, and such ethical issues as the handling and holding of information and consent to being screened. The panel will report to the council - which has no legislative power - within 18 months.

Ian Mundell

\title{
When silence isn't golden
}

\section{Tokyo}

ON a list of thankless jobs in science, being chair of a meeting in Japan on the ethics of human genome research must rank near the top. If you doubt it, just ask Norio Fujiki.

Fujiki, a member of the faculty at Fukui Medical School on the Japan sea coast, received a grant for just such a conference from one of the leaders of Japan's Human Genome Project. But the two-day seminar last month at Fukui confirmed Fujiki's worst fears: his colleagues had so little interest in the subject that they spent the first day discussing the scientific and clinical aspects of the project and then left before the talk turned to ethics.

Kenichi Matsubara provided funding for the conference by assigning 1 per cent of his $\$ 3$-million a year grant from the Ministry of Education, Science and Culture to a small group led by Fujiki. Unlike the US National Institutes of Health, which is devoting some 5 percent of its $\$ 103$ million genome budget this year to research on a variety of ethical, legal and social issues, Fujiki is almost alone in receiving money to examine these questions. Nearly all of his $\$ 30,000$ grant was spent on organising the seminar, which was held for the second time this year.

To attract life scientists to Fukui, Fujiki devoted the first day of the seminar to an overview of genome research and to scientific presentations on clinical applications of medical genetics. The second day examined social, legal and ethical issues. But, much to the dismay of Fujiki and other bioethicists, most of the life scientists among the speakers and audience did not return for the second half of the seminar.

In fairness, Fujiki points out that some of the speakers, including Matsubara, were busy negotiating with the government on funding decisions that had to be made before the end of the fiscal year on 31 March. But he admits to being "so disappointed" with the poor attendance on the second day, and he blames himself for failing to balance the programme better.

Daryl Macer, who teaches a course on bioethics at Tsukuba University, says that many of the scientists who made presentations on the first day were incapable of communicating well with their audience.
He says that their highly technical talks went over the heads of the 150 people, many of them nonscientists, who attended the meeting because of its supposed focus on ethics.

Apart from Fujiki, the only other group with government support to examine such issues is that led by Tadami Chizuka, professor of European history at Tokyo University. Chizuka and a colleague from Tsukuba University received a grant of $¥ 5$ million (US\$37,000) last year from the Ministry of Health and Welfare to translate French and German legislation on the human genome project into Japanese.

Japanese scientists are reluctant to discuss ethical issues because they lack expertise on such matters, according to one genome researcher. They also worry about being viewed as too political if they become involved.

The medical community also has shown little interest so far in the subject. Although there are bioethics committees in nearly all of Japan's hospitals and university medical departments, Chizuka says that they are not looking at issues raised by the human genome project because gene therapy has not yet reached the point of practical applications.

David Swinbanks 